\title{
Long-term trend of the ionospheric F2 layer peak height at a southern low latitude station
}

\author{
Nieves O. de Adler ${ }^{a, *}$, Ana G. Elías ${ }^{\text {b,c }}$, Teresita Heredia ${ }^{a}$ \\ ${ }^{a}$ Dep. de Física, Facultad de Ciencias Exactas y Tecnología, Universidad Nacional de Tucumán, Tucumán, Argentina \\ ${ }^{\mathrm{b}}$ Consejo Nacional de Investigaciones Científicas y Técnicas, CONICET, Argentina

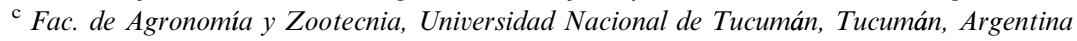 \\ Received 6 July 2001; received in revised form 16 October 2001; accepted 19 October 2001
}

\begin{abstract}
The trend of the peak height of the ionospheric F2 layer, hmF2, during three solar cycles (1957-1986) at Tucuman $\left(26.9^{\circ} \mathrm{S}\right.$, $\left.65.4^{\circ} \mathrm{W}\right)$, station located at the southern peak of the equatorial anomaly, has been estimated. hmF2 was calculated from $\mathrm{M}(3000)$, foE and foF2 records at $12 \mathrm{LT}$ using Bilitza equation, which has been tested with real height values obtained from more than 200 rescaled ionograms. The anomalies, $\mathrm{hmF} 2 \mathrm{~A}$, calculated as the deviation of experimental hmF2 values from that calculated assuming a linear dependence between $\mathrm{hmF} 2$ and the sunspot number, were estimated. The cumulated periodogram of hmF2A indicates a non-random behavior, within a 95\% confidence level. After removing the effect of solar cycle variations and periodicities of less than 5 years, hmF2A shows a mean decrease of $0.2 \mathrm{~km} / \mathrm{yr}$ (6 km in 30 years). A decrease of $14 \%$ in the maximum ionospheric electron density, NmF2, was also observed at the same station for the same period in a previous work of the authors. The lowering of hmF2 and $\mathrm{NmF} 2$ observed at Tucuman, are greater than that expected from the theory of a sinking of the upper atmosphere, due to a cooling in the thermosphere produced by the increase in $\mathrm{CO}_{2}$ concentration. (c) 2002 Elsevier Science Ltd. All rights reserved.
\end{abstract}

Keywords: Long-term trend; Cooling; Sinking; Ionosphere

\section{Introduction}

Since the beginning of the 1990s attention has been focused on long-term trends, not associated to the 11year solar cycle, in upper atmospheric parameters. One of these trends is the possible middle and upper atmosphere cooling. The increase in greenhouse gases concentration would produce a tropospheric heating and a stratospheric and mesospheric cooling. A doubling in $\mathrm{CO}_{2}$ concentration would produce a cooling of 8-15 K in the stratopause, according to the bidimensional model of Brasseur and Hitchman (1988). This variation would be of 10 and $50 \mathrm{~K}$ in the mesosphere and thermosphere, respectively, according to Roble and Dickinson (1989) model.

The upper atmospheric cooling would produce a sinking of the upper atmospheric layers. Based on the work of Roble and Dickinson (1989), Rishbeth (1990)

\footnotetext{
${ }^{*}$ Corresponding author. Present address: Quito 2499, 4107 Yerba Buena - Tucuman, Argentina.

E-mail address: nadler@infovia.com.ar (N.O.de Adler).
}

estimated a $15-20 \mathrm{~km}$ lowering of the peak height of the ionospheric $\mathrm{F} 2$ layer, $\mathrm{hmF} 2$.

hmF2 decrease was observed in ionospheric data of the Northern Hemisphere. Ulich and Turunen (1997) found for Sodankyla $\left(67.4^{\circ} \mathrm{N}, 26.7^{\circ} \mathrm{E}\right)$, for the period 1958-1994, a decrease in hmF2 of $14.4 \mathrm{~km}$, at a rate of $0.39 \mathrm{~km} / \mathrm{yr}$. Bremer (1992) observed an $8 \mathrm{~km}$ decrease, at a rate of $0.24 \mathrm{~km} / \mathrm{yr}$, in Juliusruh $\left(54.6^{\circ} \mathrm{N}, 13.4^{\circ} \mathrm{E}\right)$ for the period 1957-1990.

Regarding the Southern Hemisphere, Jarvis et al. (1998) analyzed monthly median $\mathrm{hmF} 2$ values at each hour of the day from the Argentine Islands observatory $\left(65^{\circ} \mathrm{S}, 64^{\circ} \mathrm{W}\right)$ and Port Stanley $\left(52^{\circ} \mathrm{S}, 58^{\circ} \mathrm{W}\right)$ during the period 1957-1995. They estimated the hmF2 trends separately for each month. These trends are downward at nearly all times at both stations although the decreasing rates are not constant across season and time of day. For most of the year, the downward trend is between 0.1 and $0.4 \mathrm{~km} / \mathrm{yr}$ at both sites.

Foppiano et al. (1999), using data from Concepcion $\left(36.8^{\circ} \mathrm{S}, 73.0^{\circ} \mathrm{W}\right)$ for the interval $1958-1994$, found a decrease in $\mathrm{hmF} 2$ from midmorning to midnight with rates of -0.2 to $-0.5 \mathrm{~km} / \mathrm{yr}$ depending on the season, 
and an increase of $0.5-1 \mathrm{~km} / \mathrm{yr}$ between midnight and midmorning.

Upadhyay and Mahajan (1998) found negative, positive and null trends in $\mathrm{hmF} 2$ from the analysis of data from 31 stations. They conclude that there is no definitive evidence of any global long-term trend since 1958 in hmF2.

\section{Data analysis}

In this work it is analyzed the long-term behavior of noon monthly median of $\mathrm{hmF} 2$, which was calculated from monthly median $\mathrm{M}(3000)$, foE and foF2 data. These parameters were recorded during the periods 1957-1961 and 1963-1986 (1962 was excluded from the analysis for having an incomplete record) at Tucumán $\left(26.9^{\circ} \mathrm{S}, 65.4^{\circ} \mathrm{W}\right)$, a low-latitude station, placed at the southern crest of the equatorial anomaly $\left(15.5^{\circ} \mathrm{S} ; 3.8^{\circ} \mathrm{E}\right.$ geomagnetic coordinates).

The persons who operated the ionosonde were the same during the whole period, as well as the equipment, its location and the interpreters of the records.

$\mathrm{hmF} 2$ can be estimated from ionograms using an inversion method, or by empirical formulas based on ionospheric parameters routinely recorded. The inversion methods, which give the more accurate real height values, need rescaled ionograms, which implies a hard task. For this reason, the empirical relations are preferred when the amount of needed hmF2 data is great. The empirical formula used in this work is that given by Bilitza et al. (1979):

$\mathrm{hmF} 2=\frac{1492}{M(3000)+\Delta M}-176$

with

$\Delta M=\frac{f_{1} f_{2}}{\frac{\mathrm{foF} 2}{\mathrm{foE}}-f_{3}}+f_{4}, \quad f_{1}=0.00232 R_{12}+0.222$,

$f_{2}=1-\frac{R_{12}}{150} \exp \left(-\left(\frac{\Psi}{40}\right)^{2}\right)$

$f_{3}=1.2-0.0116 \exp \left(\frac{R_{12}}{41.84}\right)$,

$f_{4}=\frac{0.096\left(R_{12}-25\right)}{150}$,

where $R_{12}$ is the sunspot number and $\Psi$ is the dip latitude.

To validate this formula, the real peak height estimated with Bilitza formula has been compared to that obtained with POLAN inversion method (Titheridge, 1985). This method has been applied to more than 200 rescaled ionograms of different hours and different solar activity levels. The correlation coefficient between hmF2 estimated with Bilitza formula and that from POLAN is
0.96 , indicating that the Bilitza formula is appropriate for Tucuman data. The strong seasonal variation of monthly median hmF2 can be filtered by using both the annual mean and the 12-month running mean data series. Since $\mathrm{hmF} 2$ is strongly influenced by solar activity, it is necessary to filter out the solar activity effect in order to look for any long-term change. The anomalies $(\mathrm{hmF} 2 \mathrm{~A})$, deviation of the experimental data $\left(\mathrm{hmF} 2_{\exp }\right)$ from the theoretical values $\left(\mathrm{hmF} 2_{\mathrm{th}}\right)$, were calculated for the annual and the 12 month running-mean data series, obtaining series $\mathrm{A}$ and $\mathrm{B}$, respectively. The theoretical values were estimated assuming a linear dependence between $\mathrm{hmF} 2$ and the sunspot number (considered as a solar activity proxy), through the equation $\mathrm{hmF} 2_{\text {th }}=$ $a+b R_{z}$, where $a$ and $b$ are constants. hmF2A is calculated then from

$\mathrm{hmF} 2 \mathrm{~A}=\mathrm{hmF} 2_{\exp }-\mathrm{hmF} 2_{\mathrm{th}}$.

The cumulated periodogram of hmF2A was estimated in series $\mathrm{A}$ and $\mathrm{B}$, with which we reject a random behavior within a $95 \%$ confidence level.
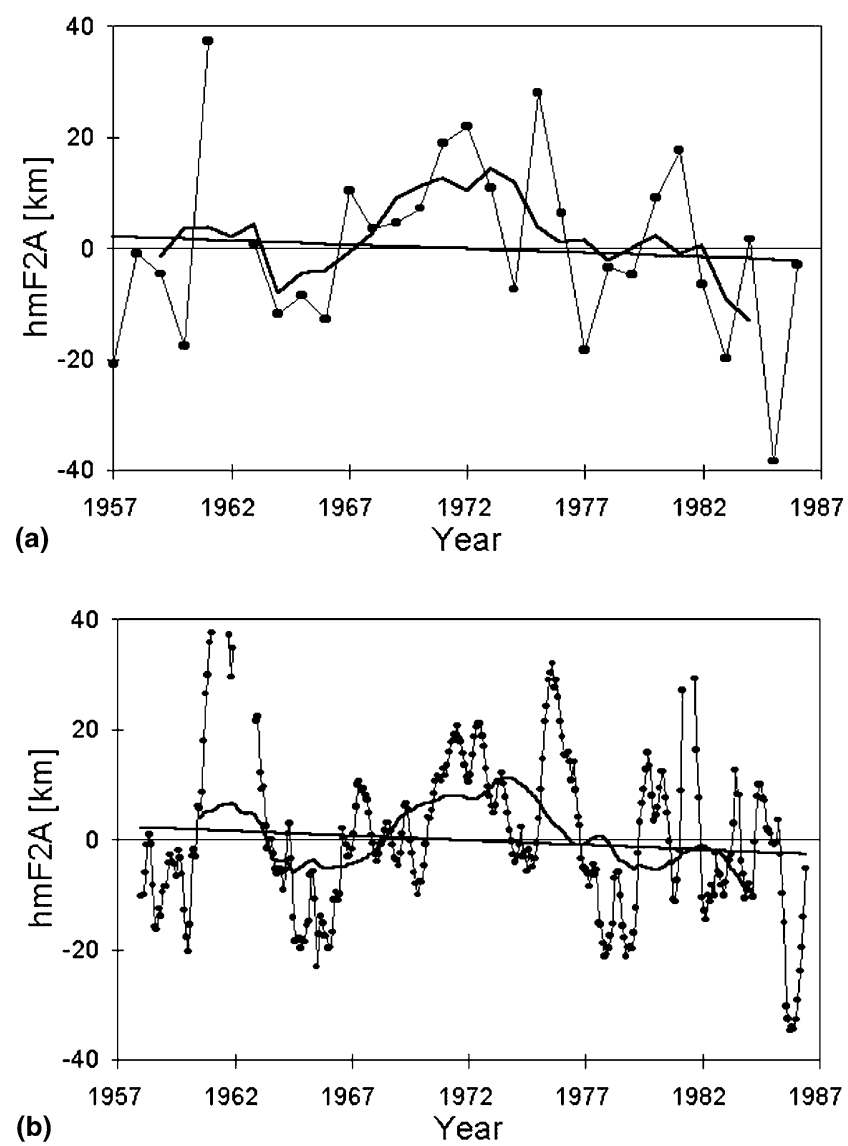

Fig. 1. (a) Annual hmF2A - series A - (black circles), 5-year runningmean of A - series C - (red line), and linear trend during 1957-1986. (b) Monthly median hmF2A - series B - (black circle), 5-year runningmean of monthly hmF2A - series D - (black line), and linear trend during 1957-986. 
The linear trend of series $\mathrm{A}$ and $\mathrm{B}$ are $(-0.2 \pm 0.3)$ and $(-0.2 \pm 0.2) \mathrm{km} / \mathrm{yr}$, respectively. The error of series B corresponds to that estimated with ordinary-leastsquare multiplied by a factor which takes into account the fact that the variable and the residuals are autocorrelated (Maddala, 1977).

The data have a big oscillation of a periodicity around 5 years which can affect the error estimation. In order to eliminate these variations, the 5-year running mean of series A and B were estimated, obtaining series $\mathrm{C}$ and $\mathrm{D}$. The trend of series $\mathrm{C}$ and $\mathrm{D}$ is the same and equal to $(-0.2 \pm 0.1) \mathrm{km} / \mathrm{yr}$ significant at a $95 \%$ level. The error in this case was estimated in the same way as in case of series B.

Fig. 1(a) and (b) show series A, B, C, and D together with the estimated trend.

\section{Conclusion}

The analysis of hmF2 data of three solar cycles (1957-1986) of a southern low-latitude station, indicates a mean decrease of $0.2 \mathrm{~km} / \mathrm{yr}(6 \mathrm{~km}$ in 30 years). This result is similar to that obtained in other latitudes (Ulich and Turunen, 1997; Bremer, 1992; Jarvis et al., 1998).

We obtained a lowering rate of $\mathrm{hmF} 2$ greater than that expected from theory based on a cooling and sinking of the atmosphere due to an increase of $\mathrm{CO}_{2}$ concentration. For a doubling of $\mathrm{CO}_{2}$ concentration, it would be expected, according to Roble and Dickinson (1989), a decrease of $50 \mathrm{~K}$ in the thermospheric temperature. Rishbeth (1990) estimates, as a consequence of this change in temperature, a $15-20 \mathrm{~km}$ lowering of hmF2. Measurements of $\mathrm{CO}_{2}$ concentration at Mauna Loa Observatory - which is usually taken as a global record - (Peixoto and Oort, 1992) indicate that it has varied around $14 \%$ for the period 1957-1997. In a rough estimation, this variation of $\mathrm{CO}_{2}$, would produce only a $0.08 \mathrm{~km} / \mathrm{yr}(3 \mathrm{~km}$ in 40 years) lowering in $\mathrm{hmF} 2$.

According to a qualitative analysis of Rishbeth (1990), a global cooling is unlikely to have any significant effect on $\mathrm{NmF} 2$ values. He arrives at this conclusion because, although a stratospheric temperature decreasing would produce a NmF2 increase, the increase in the coefficient of loss of ionization at the F2 layer would cancel the mentioned increase in $\mathrm{NmF} 2$.
Adler et al. (1997) found that the NmF2 anomaly, $\mathrm{NmF} 2 \mathrm{~A}$, estimated in the same way as hmF2A (Eq. (2)), for the same ionospheric station, period and local time here analyzed, decreased by approximately $14 \%$. A similar decreasing was also observed in some of the ionospheric station considered by Upadhyay and Mahajan (1998).

The negative trend found in $\mathrm{hmF} 2$, is compatible with the theory based on a cooling of the upper atmosphere, but its rate is greater than that expected theoretically. The $14 \%$ decrease found in $\mathrm{NmF} 2$ is not expected from this theory.

\section{References}

Adler, N.O., Elias, A.G., Manzano, J.R., 1997. Solar cycle length variation: its relation with ionospheric parameters. J. Atmos. Terr. Phys. 59, 159-162.

Bilitza, D., Sheik, N.M., Eyfrig, R., 1979. A global model for the height of the F2-peak using M3000 values from the CCIR numerical map. Telecom. J. 46, 549-553.

Brasseur, G., Hitchman, M.H., 1988. Stratospheric response to trace gas perturbations: changes in ozone and temperature distribution. Science 240, 634-637.

Bremer, J., 1992. Ionospheric trends in mid-latitudes as a possible indicator of the atmospheric greenhouse effect. J. Atmos. Terr. Phys. 54, 1505-1511.

Foppiano, A.J., Cid, L., Jara, V., 1999. Ionospheric long-term trends for South American mid-latitudes. J. Atmos. Solar Terr. Phys. 61, 717-723.

Jarvis, M.J., Jenkins, B., Rodgers, G.A., 1998. Southern hemisphere observations of a long-term decrease in $\mathrm{F}$ region altitude and thermospheric wind providing possible evidence for global thermospheric cooling. J. Geophys. Res. 103, 20774-20787.

Maddala, G.S., 1977. In: Econometrics. McGraw Hill, US, 516pp.

Peixoto, J.P., Oort, A.H., 1992. In: Physics of Climate. American Institute of Physics Press, US, 520pp.

Rishbeth, H., 1990. A greenhouse effect in the ionosphere. Planet. Space Sci. 38, 945-948.

Roble, R.G., Dickinson, R.E., 1989. How will changes in carbon dioxide and methane modify the mean structure of the mesosphere and thermosphere? Geophys. Res. Lett. 16, 1441-1444.

Titheridge, J.O., 1985. Ionogram analysis with generalized program POLAN, Report UAG-93, World Data Center, NOAA, E/GC2, Boulder, Colorado, 803pp.

Ulich, T., Turunen, E., 1997. Evidence for long-term cooling of the upper atmosphere in ionosonde data. Geophys. Res. Lett. 24, $1103-1106$.

Upadhyay, H.O., Mahajan, K.K., 1998. Atmospheric greenhouse effect and ionospheric trends. Geophys. Res. Lett. 25, 33753378 . 